\title{
STS and the Importance of Being a Collective: Gill Haddow Talks with Barry Barnes
}

\author{
GiLl HADDOW \\ UNIVERSITY OF EDINBURGH
}

BARRY BARNES

\begin{abstract}
Professor Barry Barnes was a key, founding member of the early Science Studies Unit (SSU) at the University of Edinburgh. In this interview with Gill Haddow he reflects on what is was like to be part of this fertile period of scholarly enterprise with David Bloor and others and describes some of the key influences that effected his thinking such as Thomas Kuhn. The eighties were a time of political unrest and SSU, was not outwardly political in vision but was not immune. The Science Wars also had detrimental effects for some. The origin of the concept of "boot-strapped induction," or feedback loops was also being brought into existence with the idea that scientific knowledge was both self-referential and self-validating. At the center lay the most basic and enduring tenets of Barnes' thought and that was the collective and how people could never truly be independent. A reflection by Gill Haddow follows the interview.
\end{abstract}

\section{Keywords}

self-referential knowledge; anti-individualism; collective action; performativity

\section{Dim and Distant Memories: Teaching, Friendships and Making (it) Up}

GH One of the first questions I'd like you to reflect on is basically what brought you to become involved in STS. How do you understand it, what's your early memories, that kind of thing?

BB I go back way before STS was widely recognised as a label at all. My first job was at the newly founded Edinburgh Science Studies Unit in 1967.

GH Do you remember who was there at the time?

BB David Edge had been appointed Director and I was among the first staff appointments. The unit was intentionally interdisciplinary and you could say I got "the sociology job." I was initially second choice, but the guy who was first offered it pulled out: I never found out why. Anyway they were right not to leap at me, since my qualifications were thin to

'Gill Haddow, Email: gill.haddow@ed.ac.uk

Copyright (C) 2018 (Gill Haddow, Barry Barnes). Licensed under the Creative Commons Attribution Non-commercial No Derivatives (by-nc-nd). Available at estsjournal.org. 
say the least, even by the standards of the time. Today of course you have to have a $\mathrm{PhD}$ and two years' postdoc or whatever. I merely had a year in sociology, albeit a really great year.

GH What was your favorite thing in sociology?

BB I was at Essex for a year learning it from scratch, I'd been a scientist. I'm a trained chemist [invaluable when I got interested in genomics late in life] but had no previous background in the social sciences at all. Sociology at Essex was wonderfully interesting with a very large group of graduates, and varied and talented staff of whom Alasdair MacIntyre is probably the one I learned the most from.

GH The philosopher Alasdair MacIntyre?

BB The sociologist Alasdair MacIntyre. It's the same one: he was a chair of sociology at Essex. He thought better of it later on and reverted to philosophy.

GH So he was a sociologist?

BB Yes; and particularly interested in Marx at the time. But whatever he focused on he was an outstanding teacher. I owe him a great deal.

GH Did you have any Marxist tendencies when you were at Essex?

BB No, unless you count recognising Marx as an interesting and important writer who could be learned from. I'd come to Essex convinced of the importance of the social sciences but with only the vaguest idea of what they did. I wanted to learn about them and made a start by hoovering up whatever came my way. I did get a mite more critical as time passed. I was able to do this through being awarded a conversion grant: the government wanted to get people from natural scientific backgrounds into the social sciences at that time. That was my first piece of good fortune. The second was getting the post at the Science Studies Unit, which turned out to be a great place to work, and in particular to do research. The SSU was organised as a teaching unit; the teaching was almost entirely of science [and engineering] undergraduates; and the brief was to teach more or less anything of likely relevance to them other than science itself. No doubt all this reflected the traditional Scottish vision of education that opposed undue specialisation and exclusively instrumental objectives. Whatever, the result was a terrific system both to teach and to research in. One was bound to colleagues in a shared project, but not in competition with them in the context of a single field or discipline. And in the early years of the Unit there was little or no pressure of an administrative sort either, not least because David Edge, despite a heavy teaching load and his own interests to pursue on the links between science and the media, religion, technology and engineering, was an enthusiastic participant in university administration, happy to take much of that load from us and to deal with any unwelcome external pressure. As someone with no previous experience I was particularly grateful for this: I spent my first year writing lectures in what in the UK was a largely non-existent field and scarcely had time to do anything else. Typically I'd finish writing a lecture the night before giving it, and after the scientists had finished their labs they would come over to listen to the lectures, which they seemed to like. 
GH What were you teaching at that time?

BB We were drawing materials from philosophy, history of science, sociology and other social sciences, science policy and several other areas. Don't rely on my memory on this, it is not to be trusted and this was decades ago. But I guess I was the person who had the least existing material to draw upon, although there was the group around Bernal in the UK, and in the USA a small but very productive specialty of sociology of science. Also there were historical and philosophical studies of science I could make use of. Even so, I had to read very widely and it was a relief to get to the end of the first year with a passable set of lectures written up for future use-and future improvement. After that things eased up and further support to continue on the road I was taking came when Tom Burns, the Professor of Sociology, commissioned me to prepare a reader in sociology of science. Tom Burns had a way of being supportive in a distant and unobtrusive way; and I guess I owe rather more to him than I knew at the time.

GH Did you know what you were looking for or could you give me an example?

BB I read quite a lot of history, some of which was institutional and structural, some of which was in a loose sense Marxist-Needham's stuff on science in China for example. I got to know the work of the Bernal group much better when Gary Werskey eventually joined the staff, since he was at work on a book about them. They were all committed to a Marxist and utilitarian view of science and its value, and they wrote of it as scientists, with what was in the last analysis a descriptive perspective that I could connect with even if I didn't wholly share their viewpoint. I was looking for material that was describing human beings doing things and trying to understand what was going on, and they got halfway there at least if not more. I had a lot of time for their work, and much less for that of their critics, some of whom seemed to me entirely lacking in empirical curiosity-lacking in any sense that there was something to be learned from looking at what scientists actually did.

GH Was there anyone in particular, the critics of that group that you had an issue with?

BB Much of the philosophical criticism didn't attract me because of this, but fortunately not all philosophy is devoid of empirical curiosity and I learned from David Bloor where to go for interesting and valuable philosophical work. I shared an office with him at this time and talked with him a lot, and I went to his undergraduate lectures on philosophy of science. We were all going to each other's lectures in the first year.

GH I wanted to ask you about sharing an office with David, how was that? How long did you hang out together and share an office?

BB I can't remember how long but it was certainly for a significant period of time. David was a wonderful colleague. We eventually got an office each, but the initial period of working together like that was invaluable, for me at least-another fortunate accident to add to the list I suppose you could say. He and I talked a great deal, basically about how to understand science as human behaviour. We would swap ideas and compare one with another. I was getting increasingly familiar with social science literatures as time passed, anthropology more than traditional sociology, and micro sociology more than macro. 
Mary Douglas and Howard Becker come to mind but there were several others. David was not only into philosophy of science and mathematics, he was doing a $\mathrm{PhD}$ in psychology. But the work we came increasingly to talk about in relation to science was that of Thomas Kuhn, who could be read in all kinds of different ways, whether as historian, or philosopher, or sociologist. Kuhn's work became very important in the unit, not least as a teaching resource. For the first time here was someone taking a serious look at scientific training and pointing out that science is crucially dependent on inherited knowledge and trust in the ancestors. You way well think this is an obvious point, but in insisting on its epistemic significance at that time Kuhn managed to scandalise a lot of academics, especially when he made explicit parallels between the teaching of science and the teaching of theology. He certainly didn't scandalise science students though. We must have taught thousands of them over the years-and yet I can only recall one who found Kuhn's work disturbing. Many seemed to think his account of the role of ancestry and authority described their day to day experience, and some even wondered why it was being pointed out. The guy I remember having a problem with it was a follower of Teilhard de Chardin, and it wasn't the technicalities of how you learn science that were the issue in his case. Kuhn was also invaluable in our research. He's famous for his discussion of scientific paradigms, but it wasn't always properly understood what a paradigm was. He himself identified a paradigm as an exemplary achievement or exemplar. It is a proposed solution to a particular problem or puzzle that a group of scientists agree upon as the correct or best available solution and deploy as a model in efforts to solve related problems case by case. It's a wonderful insight. An exemplar is something that's at once the product of our encounters with the world outside us and our encounters with each other in collectives. It combines in one unit things that had previously been separated as either "individual" or "social," products of "reason" or products of "authority." And that one unit is identified both as the fundamental unit in which scientific knowledge is transmitted from generation to generation and the basic resource of researchers, who extend it to new problems in contingent moves from one to the next involving open-ended analogies. Of course there are a number of routes to a view of research of this sort, which is to a finitist view, and we didn't just explore this one. But it was particularly helpful in clarifying our existing thinking and presenting a coherent readily intelligible alternative to the ubiquitous dualist frameworks of the time. Today of course dualist frames are easily dispensed with, even if they remain more widespread than they deserve to be. But arriving at a memorable, alternative vision of things, one which made scientific knowledge and its carriers intelligible just as other forms of knowledge and their carriers are intelligible, felt like a significant step forward at that time. As the social scientist in the place, I now felt like I had some understanding of scientific tribes-one which combined my longstanding admiration of them, their culture and their capabilities, with recognition that as locales of human belief and behaviour they could be studied sociologically just as others are. 


\section{From SSU to STS}

GH I think that's wonderful that at this point. But at this point, this was the Science Studies Unit, it seems to be fairly small, heavily influenced by teaching.

BB Four permanent staff, including the boss, and two [first rate] administrators. That was the size in the early days and it didn't change much for a long time

GH I think there's about 50 now here. Did you ever anticipate that it would end up being quite as well known and renowned as it is now? How important is the Science Studies Unit to the development of STIS do you think? It seems to be really key.

BB I don't know the answer to this question, and can tell you very little that would help you to answer it. You need to ask other people. So far I've tried to describe a tiny bit of what went on in the period when the SSU was getting up to speed, the tiny bit that I'm guessing may interest you most. But you are now asking about the $80 \mathrm{~s}$ and $90 \mathrm{~s}$ and the changes that occurred over those decades. The 80 s were a period when I was getting obsessively involved in research in a buzzing environment. Steve Shapin had taken over "the history job," I'd met Colwyn Trevarthen for the first time, even though he'd been around for years, a few hundred yards away in the psychology department. Donald Mackenzie had a permanent appointment in the Sociology Department--Tom Burns once more, as supportive and distant as ever. There were lots of other truly interesting colleagues around. I was aware that "science studies" type work was ongoing elsewhere, of course, and of its increasing diversity. And I admired some of it a lot, the work of Harry Collins and Trevor Pinch at Bath being just one example. Even so, I guess I should have been more outward looking, but there were other things to divert attention even when I did look around. The country was being devastated in the early 80s--transformed as some might prefer to say. And the wrecking balls swinging outside were at work inside the universities as well. Their independence was lost, massive job losses were occurring, the social science research council was set to be abolished altogether but the sentence was eventually commuted to humiliation, exile - and a name change. Not even the natural sciences escaped damage: some very senior politicians were hostile to the entire university system as it stood. We shouldn't allow ourselves to forget what kind of people these were and what kind of a world it was then. Geoff Palmer, one of the few black scientists in my generation to make it big time, has just recalled in a BBC interview how early in his career Sir Keith Joseph told him to go back to Jamaica and grow bananas. It jogged my memory, but might be even more interesting to people with no memories of the 80 s to jog. Anyway, I'm digressing. The name of the game in the universities in the early 80 s was survival. The unit did survive of course, the main change being that at the end of this period it lost its Director, David Edge, and subsequently moved out of the science faculty into the sociology department. Tom Burns had retired and Colin Bell was head of department, working on migration and the vast movement of populations into Europe he reckoned was bound to occur in the not too distant future. The move didn't work out all that well, and I guess some of the fault was mine. I didn't 
foresee the extent of the culture clash that would be involved. Moving to the 90s, I can help you even less because I left Edinburgh in 1992 and moved my work away from science at the same time, only coming back to it in 2002 as a co-director of Egenis, in the network of genomics research centres with its hub at Edinburgh. It felt to me that in that decade science studies had changed enormously, but I didn't understand how or why. I found myself swimming in a sea of cash for the first time ever, but swimming in a sea of bureaucracy as well. Some of the administrators in the centres themselves were quite brilliant, invaluable in fact, worth every penny, as they had been in the old SSU. But elsewhere a system was proliferating supposedly to ensure efficiency, relevance and accountability. Perhaps it did have some positive value and was more than a job creation scheme for box tickers and empire builders, I don't know, but it certainly wasted a lot of the time of the people doing the actual work. It helped me realise how the old fashioned set up in the SSU had actually helped to make it remarkably efficient - to sustain substantial teaching programmes and generate significant research contributions on a shoestring. But I'm in no position to compare objectively the merits of the old arrangements I was used to, and new ones I never felt entirely comfortable with. Paul Forman may perhaps be right about what had happened. He claims that secular social changes have resulted in rejection of traditional discipline based boundaries, a reversal of the science-technology hierarchy so that technology now comes first, and the valorisation of utility rather than rigour, all of which adds up to a shift in the academy from the modern to the postmodern. Much of this occurred, he says, in the 1980s and is now irreversible. To me it felt like this kind of this shift occurred in the $90 \mathrm{~s}$ in "science studies." What I left in 1992 was entirely different organisationally to what I returned to ten years later, as I've described. But it was different culturally as well, also in a way that resonates with what Paul says. Before I left I was used to criticism of the Unit as a threat to important disciplinary boundaries, to rational argument, and even - believe it or not to science. Ten years later it seemed to have become part of the established order, now criticised precisely for being interdisciplinary when the very existence of disciplines was part of the problem, as well as for being scientistic and reactionary.

GH This is it, a certain irony.

BB Dead right. Anyway, all this left me in no doubt that there was a major discontinuity between the organisation and culture of the old SSU and those of ISSTI and the genomics research centres, and that what we have now can't be understood purely and simply as an expansion of what existed before. I'm tempted to see it as the kind of change that Paul has described, - and he could even be right in identifying it as irreversible. But I was out of the loop when the big changes were actually occurring in the 90s and can't provide you with any reliable information on what happened prior to what you yourself will have experienced as the rise of STS. 


\section{Political Animals in SSU ...}

GH I wondered if you'd say a few words about politics, feminism, that sort of... Politically the Science Studies Unit didn't seem to be a political animal at all.

BB Interesting you found that. I think it was true of the time I was there as well - quite remarkable in a way given that immediately it started students began rioting all over the place. Of course it was definitely political in one sense. Relativism, naturalism, scepticism, empiricism, materialism are some of the words that come to mind to describe the ethos of the Unit, all alike in giving bottom-up accounts of knowledge and society that have always had an important political dimension as their historians have shown us. So from that point of view there is a politics implicit in what the Unit was doing, but it wasn't political in the usual sense; it wasn't up front political. For myself, I deliberately kept my political views out of my work, although I have to confess it was a little time before I had any political views to keep out. Even so, living in interesting times inevitably has its effects. I've already said enough about the interesting times in the 80s. I guess that was the time I figured that sociology had made a big strategic mistake in how it studied poverty: to understand poverty you need to study the rich. But I was also part of the last generation to reach adulthood in time to live through the Vietnam war. It was an appallingly vicious war, and in its last few years with the outcome clear thousands of people died in what was little more than an attempt at face-saving. Living through the years it lasted was an education. Among other things, it left me with an enduring suspicion of male politicians with weapons at their beck and call, particularly nuclear bombs, particularly males from Texas. Perhaps we should shift the glass ceilings over to men and give more women a try. They could scarcely do any worse in high political office; perhaps they'd only kill when there was some point to it. Anyway, joking aside, you can see what I'm getting at. Were there political animals in the SSU? Yes. Was the SSU a political animal? It depends what you mean by politics.

\section{... and the Politics of The Science Wars}

BB One intriguing thing I remember about the early period of the unit was that not only critics and enemies but even allies were extremely reluctant to believe that it wasn't a political animal, and too ready to believe accounts of it as some sort of political project. This led to persistent misunderstandings of what it was all about. There were people for example who sincerely believed it was anti-scientific-why otherwise wasn't it telling people what was so special about science? Similarly, some academics assumed it must be engaged in a turf war with them, and all being fair in love and war deliberately misrepresented what it was doing. Of course the misrepresentations were read by other people who innocently accepted them as correct. Once accounts of this sort get established they can persist for decades; outside their special areas academics tend to accept what they read without checking it out. So decades after this early period lots of the nonsense that had been written about us was recycled, hardly modified at all, in the 
so-called science wars. We found ourselves denounced along with French intellectuals, feminists, postmodernists and other supposed purveyors of irrationalism and antiscience.

GH How did that feel at the time? Do you remember how that felt at the time for everyone?

BB There were people whose careers suffered very badly and unjustly as a result of the science wars and the careless polemics of the scientists, but fewer in Europe than the USA. They were at their height in the 1990s but I was scarcely involved in them at all. I knew that David was rebutting criticisms of the SSU and had repeatedly dealt with the significant misunderstandings. The critics only had to read him, but apparently very few of them did and nothing changed. Of course, David remained completely unshaken in his views as well, but as always he was remarkably thorough and looked at criticisms in proper detail before responding. Anyway, I soon figured out there was little point in getting involved and for the most part I kept out of it all. There was one occasion when I met Alan Sokal and Jean Bricmont: it was at a conference very late on, intended to promote peace and reconciliation. The French seemed to have got worried about their intellectuals. It was clear that Sokal and Bricmont assumed that as a former SSU person I had been one of the wicked relativists who'd fought in the enemy army. They were surprised by what I told them about the SSU and my own longstanding positive view of the natural sciences. I remember Bricmont saying something like, "if this is how you feel why aren't you propagandising on behalf of science like I am?" And I said to Bricmont, "well, because I'm not into propagandising." I never saw them again and our convivial chat had no significant consequences at all. Even so, I'd have liked to talk some more to them, particularly to Bricmont, who was a fascinating character and a bit of a one-off.

\section{Boot-strapped Induction, Finitism, and Reflexivity}

GH Thinking back to the early things that you've published, what's been one of your favorite topics to write about or to deal with or what's been some of your favorite outputs, papers or publications? Mine is "bootstrapped induction" for instance, that's one of my favorite things that you've written.

BB Did you read that? Oh how I struggled with that paper. It came out in 1983 but it took ages to write and it's important to understand the context. By that time I'd figured I had something like an okay sociological understanding of science and scientific knowledge. What was to be done with it? Certainly not wander around debunking science. The idea now became to see how readily it would be applicable elsewhere, - whether our finitist treatment of science could now serve as an exemplar for social scientists in the areas we ourselves had initially learned from, and borrowed from. So I started out on this, initially looking at anthropological studies, and arguing that a finitist account could be applied to the classification schemes and shared beliefs they had documented. Finitism was, incidentally, by no means a new development in philosophy or the social sciences, but only a few people had explored it with vigour and genuine determination. Most people 
tended to dislike it and preferred to take other pathways; and my [our] version was found especially uncongenial because not only did it make the standard finitist point that future applications of knowledge couldn't be reliably inferred from past ones-that pro forma people made them up as they went along as it were--it also highlighted the epistemic implication here, that shared classification schemes and bodies of knowledge scientific or otherwise--couldn't be carried by independent individuals: interacting collectives were required to sustain them.

GH It seems to have lasted the test of time, seems to be going still pretty well just now.

BB That's good to hear, because you know more about now than I do: I'm years out of date...Anyway, efforts to use scientific knowledge as an exemplar also exposed problems and apparent exceptions. Scientific knowledge is knowledge of the world around us and refers, so we assume, to things out there. We look at or act upon the things we refer to in order to check whether our references are correct or not. But if you're a sociologist your study of human activity is itself human activity and you're constantly generating a stream of new referents for your knowledge as you apply it. And you're also constantly encountering referring activity in everyday discourse, with referents that in terms of the exemplary case are obscure to say the least. So you get acutely sensitised to problems here--or at least I did--and, they turned out to be due to the existence of self-referring activity that it nowhere allowed for. Here's the provenance of the 1983 paper on bootstrapped induction, self-reference and self-validation. And it proved a very difficult paper to write partly because of the absence of helpful literature even in the social sciences, where systematic discussion of the topic, amazingly, scarcely existed, although penetrating illustrations and investigations of it did exist, in areas like ethnomethodology for example.

GH Do you mean like reflexivity?

BB Yes, I guess one way to some of the most helpful material would be to Google reflexivity. But it wasn't just the literature problem that made the paper hard work. The topic was a difficult one, I was too sparing in the initial assumptions I was prepared to make, and I took on too much at once. So I ended up more with a sketch to serve as a memoir for future work. What began as thoughts on a little local difficulty became an exploration of the nature of institutions and the statuses incarnate in them-entities existing through and as the self-referring knowledge constitutive of them. It's quite amazing on reflection how little of our knowledge of things is validated according to the usual stereotype, by taking a close look at them or poking around with them, and how much is validated by looking elsewhere, at how we treat the things in question [other members where social statuses are concerned], or at their physical context, as with holes or islands or planets.

GH I'm going to read it again, have you re-read it recently?

BB It's far too difficult for me these days. And it seems to have been difficult for other people as well because it was quite a long time before people started engaging with it. I guess Donald was one of the first people, which was good for morale as I've always had enormous respect for his judgement, and then it was nice to find John Searle coming to 
some broadly similar conclusions entirely independently a while later. But I produced simpler accounts of the basic themes as I developed the ideas in it. There's one of them in the book on power I published in 1988. Nobody's interested in that book any more but it's one of my best books.

GH What is it you liked so much about it? Is it the fact that you're dealing with something, power now is all about Foucault, for instance etc.

BB I like Foucault on power a lot, but even in Foucault, whose historical sociology was much more illuminating than contemporary writers on power in the English speaking world, it isn't altogether clear what power is supposed to be. That was what my book focused on, elaborating on ideas in the 1983 paper. At that time social scientists here and in the US thought they were writing on power when they weren't. Look at Mick Mann on the sources of power. He lists economic, ideological; military and political power. Other writers ask how we know power exists at all and tell us we can infer that from its effects. They then go on to explain these effects by citing the power the existence of which they have just inferred from them -and saying little more about it. There's something not quite right about all this.

GH Go round again.

BB Exactly. These accounts of power went round in circles, assuming what they tried to explain. I wanted to break out of the circle. I was willing to take some things for granted, but not to write a book on power that never made clear what I was talking about. I made some assumptions of course. That I have a capacity to act on the world, for example, embedded in my skeleton and musculature, and can use it to knock that glass of water over or kick your filing cabinet. And if you want to call those capacities powers, even to say they are my powers, that's ok. Everybody has powers / capacities of that sort; but take a second or two longer to look around and it's clear that individual capacities only add up to a minute proportion of the powers of human beings. Where do the other powers come from? Humans multiply and amplify their powers/capacities through coordination. Where does coordination come from? It comes from the possession of shared knowledge. And what's the knowledge that is shared? It's everything that members of the sharing collective know, but crucially it includes the intensely selfreferring knowledge that I was trying to describe in 1983. The sciences are wonderful exemplars of all this, and were of course in the back of my mind all the time, although they're rarely mentioned in the book. I gave a simpler account of self-referring knowledge in this book, to underpin the basic thesis about power:...that it's by virtue of a distribution of knowledge holding over a collective, and being held in place by that collective itself operating as an interacting membership, that individual powers are amplified...to the point where a membership can do all the amazing things that actual human beings do everywhere, things which disconnected human beings would be utterly and completely incapable of doing. That's the message, although it didn't attract much interest at the time.

GH Why do you think that is? 
BB Lots of possible reasons, but one is that at this time the social sciences, including sociology, had become unduly individualistic. I had tried to write the Power book so that it was accessible to people with individualistic habits of thought: just assume that people share knowledge, I was saying much of the time, and you will get it, the rest will follow ok. But eventually I have to ask how we should understand shared knowledge itself, and point out that it can't exist if humans are independent rational calculators. How could they calculate they needed it prior to having it? In a nutshell, whatever makes for knowledge generation must be primeval. And what was primeval I identified as human sociability, the susceptibility of humans to each other in interaction. Humans constantly affect each other causally in interaction, allowing them to coordinate their cognition and their activity, as independent rational agents, if such existed, never could. Whenever humans are encountered it is in already coordinated, knowledge sharing groups able to act collectively to preserve and sustain that knowledge and to exercise the powers that its existence affords them. This is what being human always entails. But this was a time when individual agency was being celebrated to such an extent that philosophers and sociologists would both proclaim it as their chosen metaphysics and chide anything that conflicted with it as a failure to take account of its existence, as though it was round the place somewhere and you'd failed to notice. Anyway, the power book didn't exactly celebrate individual agency.

\section{Putting Individualism in Its Place}

BB Once you get deeply into a line of research you can get the feeling of being led on almost without thought from one problem to the next and find yourself going places remote and unimagined when you started. And it becomes easier to move along lonely paths with lots of people walking in the opposite direction. That's a bit like how my research went after the power book, so again I'm detached from the changes that mainly interest you. Not detached altogether from what other people were doing of course, but not in day-to day contact with the key people. For some reason most of the work that proved important to me over this time had been done by sociologists in the USA. The power book had shown that humans couldn't be independent, so the question now was: in what way precisely did they affect each other? I had a look through material in micro sociology and social psychology again. There's some great material there but I focused on Erving Goffman. Goffman recognised Durkheim as an important influence. And in Elementary Forms there's a description of how aboriginals periodically come together to engage in collective effervescence, as he calls it, wherein they reaffirm their social bonds and reinforce their shared categories and classifications. This put down a placeholder that Goffman and others could subsequently replace with studies of interaction and interaction ritual.

GH I think that's what I was always attracted to in your work and in Durkheim's work as well, it is about sociability and about collectiveness. 
BB Yes Durkheim is a wonderful resource, and the late work in particular. But Goffman made good use of him and improved upon him in important respects. Durkheim remarks how aboriginals felt some authoritative externality making demands on them and demanding a special respect, which they were unable to describe. So they reified it as a material entity, a sacred totem, to which they directed the respect that was due. Durkheim identified the mysterious authoritative entity as other people, those in the rest of the tribe or clan, and spoke of the totem standing in for society, as in later forms of religion God stands in for society. But Goffman was one of those who investigated the accord and withholding of respect, and identified it as something that people do largely unremarked, thereby modifying each other's cognition and behaviour literally from second to second. And these are the studies that identify the nature of the mutual susceptibility that permits the generation of shared knowledge and collective action.

GH Maybe they'll have a renaissance moment.

BB Certainly they deserve one.

GH There's definitely a theme through your work which is this anti-individualism.

BB That's right, the more I learn about it the less I like it. But whilst I reckoned I'd made a solid case against it by this time, there was one final problem that needed to be dealt with, that of its very existence. If humans are sociable mutually susceptible creatures, how come they identify themselves as independent individuals, possessed of free will, capable of choice, and so on and so forth? And again it is Durkheim who points the way to an answer, when he speaks of the cult of the individual. The concept of the independent individual is the creation of sociable human beings who impart it to each other as a model that guides how others are to be treated: in other words it is a status category. And why does this status category exist? It's part of an institution, ubiquitous in the life of humans everywhere, wherein it functions as the default status in encounters with others and a resource in the localisation of responsibility. But even if it's functional for people to wander around describing each other as independent when they're not, how come they don't notice the clash? There's no short answer to this question, or indeed to the more general question of why humans have such difficulty in distinguishing classification by status from classification by state. But a small part of the answer, as I see it in this case, is that the routine attribution of independent agency has actually adjusted to the very experience that doesn't fit it. It is when a person is susceptible to our communications, and modifies her behaviour in response that we're inclined to continue to see her as independent. Where she's completely unaffected by these communications we're likely to impute causal constraints or pathology, compulsive behaviour perhaps. Sociability get buried under discourse that ostensibly implies its opposite: susceptibility prompts belief in free will...Take a look at the quote at the very start of my book on agency. Strongly individualistic accounts of humans have a tendency to turn things upside down, as here, but it is not always harmless and it needs watching. For example, constraints on individual agency are often said to be disempowering when the opposite is the case. Attacks on the power of a group often try to convert it into so many 
independent individuals. Think of the continuing attacks on organised labour, rationalised by talk of the merits of the so-called free market. The result of freeing thousands of workers from constraint, as the rhetoric has it, has been the intended one of weakening them, so they can't resist the power of small, strongly networked groups-for example those at the top of those other deformities in the free market known as companies or corporations, often partially fabricated in schools and universities. It's worth a brief mention as well of a development imputed to strong individualism by Philip Mirowski for instance, possibly inspired by Michel Callon. Having noticed that humans, having been made free of constraint, don't always behave like independent rational individuals, "neoliberalism" as he calls it, has decided to make them free in another sense altogether. They will be trained to be free, nudged into being free, forced into it, coerced into it. If the theory doesn't fit the humans then the humans will be changed. It is an interesting idea. Susceptible agents induced to simulate independent ones? Or fully converted? Last I read, PM had got depressed by the idea that one way or the other it had worked.

\section{On the Future}

GH I think through our discussion I find that we have talked a lot about influences, about what it was like in the wider world at that time, we talked a lot about the things that you guys were writing about and publishing about why you were dealing with those kinds of works, plus the criticisms that you've received and how you dealt with that. But I guess the thing that we haven't talked about, and what the basis of this book is also about, is about the future.

BB Good to get to this question. My memory is very dodgy these days and I'm bound to have been an unreliable informant so far. But as for the future, nobody's been there. I'm actually pretty sanguine about it. Provided you don't collapse under the audit culture; and provided and we don't blow each other up it ought to be fine. And these risks exist most everywhere. What you have, both here and in STS generally, are loads of important problems to engage with - problems that are both intrinsically interesting and dosh attracting, loads of models and exemplars to extend to them, and good work ongoing that's already doing that. That's all that's needed and provides plenty of options for a successful future. Although there's an enormous demand for research on science and technology done in a strongly individualistic frame, there's an enormous supply as well, so that part of the work here done in a different frame isn't necessarily at a disadvantage. I hope particularly that work on self-referring knowledge manages to continue here-but I would, wouldn't I? Its relevance to the study of finance and economics is obvious now, but potentially it's relevant to lots of areas in the social sciences, and yet others elsewhere. To give an extreme example, my guess is that neuroscientists and brain scanners are due to run into the self-reference problem soon, they probably have already-I'm hugely out of date. Then we can expect fascinating insights into brains that 
deal with the problem without turning a hair and classify things by status as a matter of course, even though other brains have had to struggle for years to get a verbal handle on what's involved. There could be lots to discuss with the scanners, especially as they start working with two or three machines and not just one. Some of these guys are studying consciousness. It's worth recalling that consciousness is knowing with others. Of course, the future will be largely decided, as it should be, by the fifty odd people in it doing something called ST[I]S. I just hope you don't face too many external demands for long term plans on a side of A4, or abstract accounts of what's so special about what you're doing. It's hard to see very far ahead in your kind of research. And whilst boundaries help in academic division of labour, weak ones, like ISSTI seems to have within and around itself, make for flexibility, as does the wonderfully vague label STS. Where would you go that isn't STS? STS studies science and technology, which means it can scarcely avoid the systematic study of people doing things. Anthropology studies people doing things and that study has long encompassed their knowledge and technology. Most everywhere in the social sciences it's the same. What are the key differences between one locale and another? Mainly that they have different inheritances of exemplary achievements, although in academic turf wars all sorts of other rationalisations for hard boundaries are produced. A researcher might conceivably find good reasons for studying any form or aspect of human behaviour. So why shouldn't she? Not to worry, it's implicit in the title.

\title{
Performativity and the Collective
}

\author{
BY GILL HADDOW
}

In 1997 I studied at the University of Edinburgh's Science Studies Unit (SSU), where I was taught the "The Analytical Tradition" by Professor David Bloor as part of the MSc in the Sociology and Politics of Science and Technology. Professor Barry Barnes had moved on to new pastures to revisit earlier ideas, such as ideas about anti-individualism, by the time I had started, and we never met then. Barnes was a sociologist who looked at people in society as joined together, cohesive, and creative. His views may be challenging to those who see society as one that is separated and fractured; maybe as Marx once did and some postmodernists now. I defined myself then and now, as a "sunshine sociologist" interested in solidarity and the collective-how is it that despite the fractures societies mostly continue to exist? Therefore, I want to briefly focus on Barnesian performativity and two related issues regarding the inductive nature of STS inquiry and the relationship between power and knowledge. 
The first article I read by Professor Barnes was published in 1983, in the journal "Sociology." It was called "Social Life as Bootstrapped Induction." He argues that "much referring activity is self-referring and much inference self-validating." I found these ideas appealing but difficult to understand. Professor Barnes said as much in the interview when I asked him if he had read it again recently. "It's far too difficult for me. It's far too difficult for me these days," he said, "and it seems to have been difficult for other people as well because it was quite a long time before people started engaging with it." I am not sure even now that I fully understand the article; but the idea of Natural (N)- and Social (S) kind terms and the fact that the circularity and the tautology were used explicitly was counter to my assumption that both circularity and tautology should be avoided. The inductive inferences have a feedback mechanism - a bootstrap that puts them on repeat by the actors that are referring to them. As Professor Barnes wrote, repeated practice and social interaction shape the knowledge of the external referent and it is the repeated referring to the external referent as "table" that makes the table known as table (and not chair). This is a strong version of performativity that relates to how real world entities or external referents (Natural kinds of $\mathrm{N}$ types) are matched with the concepts that apply to them (the Social kinds or $S$ types) through repeated referencing to them. This referencing eventually gives the referencing itself accreditation or validation. Professor Barnes takes this further than the naming of the materiality to the actual creation of its original reference in relation to the " $\mathrm{S}$ " type. The $\mathrm{S}$ type is a social kind and is demonstrated, for example, when a traditional marriage ceremony is undertaken. The ceremony creates and changes the social reality for those to be married by naming them "husband" and "wife" and creating their new identity as such. In terms of Barnesian performativity there is room for change in the performativity that he discusses, as the self-referring is not necessarily stuck in a loop (so to speak). The children's game of "telephone," where a child whispers a story to her neighbor and it gradually becomes distorted as it is passed from one to another, can change the original reference. Barry and I discussed this in the interview.

This version of "Barnesian Performativity" that was in the article was taken up by Professor Donald Mackenzie at the University of Edinburgh. Professor Mackenzie shows that activities (finance and economics in his case) are also performative and creative; They are activities that are boot-strapped but also flexible, (as in the game of "Telephone"). . Here is the beauty of the recreation and regeneration of knowledge of the world; Barnes' theory did not make assumptions about origins but asked what the origins were of how we know "stuff." This is performativity at its most innovative but without falling into the "language constructs reality" argument that perhaps few adhere to nowadays. There is no idealism to be found in Barnes' work because there is a reality of that of which we can have knowledge-the $\mathrm{N}$ kind and the $\mathrm{S}$ kind. Language does not construct the external world, but names and refers to it.

The idea of a Barnesian performativity - a way of knowing the world but of also doing the world-is located in his belief about the power of interaction. In "Bootstrapped Induction" Barnes discusses money and financial institutions, but it was power that took his attention. Here his interest in ethnomethodology and micro-sociology drives his analysis of "power." Unsurprisingly, Barnes' method of inquiry into epistemology (knowing knowledge) resonated 
strongly with the bottom-up nature of inductive inquiry that many social scientists favored then and now-contrasting with the top-down of scientific inquiry searching for the data to support the hypothesis Indeed, the appeal of the "bottom-up" resides in the more apparently democratic way of research practice putting an inductive approach at the center. Social scientific inquiry attempts to be surprised and does not necessarily always want to find what a researcher is looking for. It is of course an over-simplification to present the way these approaches to doing social science research. In practice inductive, deductive, and abductive approaches are often at work.

With only isolated individuals there is no power; a person on a desert island has no power over others because there are no others to have any power over. Power is both generated and "amplified" in the interaction between people. For example, one can think of human ability, such as the fact that some find it easier to read than others. Power comes in when others are able to know those whose reading skills are differently abled as "dyslexic." With no others there is no dyslexia. A truism, indeed, but an important one. In my view, what is at the core of Barnes's sociology is a commitment to people and an understanding of the relationships and interactions between them that generate knowledge and ultimately, power. Is this different interpretation of Foucauldian "knowledge is power?" Barnes, during our discussion, thinks the origins of that power is in knowledge and how it is created. I guess for him "power is knowledge." Although Barnes admits for admiration for Foucault, it is to Durkheim that is his greatest influence. For Barnes, Durkheim's influence appears most strongly in a Durkheimian "social solidarity" and showing how cohesiveness is accomplished in a society of distinct and different individuals.

Thus, throughout Professor Barnes' work and life is the emphasis on the collective and, indeed, anti-individualism. In our interview, Barnes criticizes the individualism of the eighties and arguably would be uncomfortable with its appearance today in some social science thinking in economics and psychology. Indeed, he finds rational choice theory as the worst-case scenario of combining collective knowledge with individual calculus. For Barnes, there is an increasing threat associated with the "illusion of individualism"; for the human is in a collective making up a knowledge team where its validity-the knowledge worth-is agreed upon by the many. Indeed, the irony is that the collective may come from a group of individuals in any numerical form. Simply, lots of people are needed to make a community; one person on a desert island obviously does not cut it. However, the idea of individualism, of autonomy and freedom comes from the collective in the first instance. Without the collective there would be no individualism, and without individuals there would be no collective. Irony indeed.

\section{Author Biography}

Gill Haddow is a senior research fellow based in Science, Technology and Innovation Studies at the University of Edinburgh. Her interests reside in areas that relate to the sociology of biomedicine, technology and the body. Her current research project, Animal, Mechanical and Me: The Search for Replaceable Hearts, is exploring the experience of the everyday cyborg along 
with people's hypothetical views about using non-human animals, cybernetic devices and 3-D bioprinting for repairing, replacing or regenerating the human heart.

\section{Author Biography}

Professor S. Barry Barnes Barnes worked at the "Science Studies Unit" at the University of Edinburgh with David Bloor from the 1970s through the early 1990s, where they developed the strong programme in the Sociology of Scientific Knowledge. He moved to the sociology department in Exeter in 1992 before retiring. Barnes is known for his naturalistic approach to science, a view elaborated in his book Scientific Knowledge and Sociological Theory (1974). He advocated a post-Kuhnian approach to scientific knowledge, and suggested that philosophers, historians and other researchers study scientific practice in a variety of fields as cultural traditions whose development could be given causal explanations. In this view conceptual change in normal science is a process unfolding through expert debate and negotiation. This latter perspective was developed in T. S. Kuhn and Social Science (1982).

\section{References}

Barnes, B. “Social Life as Bootstrapped Induction. 1983 Sociology, 17(4), 524-545. 